\title{
Inbreeding rate and genetic structure of cat populations in Poland
}

\author{
S. Mucha • A. Wolc • A. Gradowska • T. Szwaczkowski
}

Received: 11 May 2010 /Revised: 15 November 2010 /Accepted: 17 November 2010/Published online: 3 December 2010

(C) Institute of Plant Genetics, Polish Academy of Sciences, Poznan 2010

\begin{abstract}
The objective of the study was to analyze effective population size and inbreeding level in populations of cat breeds registered in the Polish Studbook. The Association of Purebred Cat Breeders in Poland provided access to pedigrees of 26725 cats from seven breeds. The most frequent breed was Persian, however increasing tendency in numbers of registered animals from other breeds was recorded in later years. Although the percentage of inbred individuals was increasing over time, mating of close relatives was avoided by most of the breeders, and the average inbreeding coefficient exceeded $5 \%$ only for Siberian and Russian breeds. Current analysis suggests that the Polish pedigree cat populations are not threatened by negative effects of inbreeding.
\end{abstract}

Keywords Effective number of founders · Genetic diversity $\cdot$ Genetic drift $\cdot$ Inbreeding level

\section{Introduction}

Inbreeding levels of pets are not widely known. Such information would be useful to avoid negative, and enhance positive effects of breeding. Cautiously managed inbreeding levels may play an important role in genetic improvement. Such an improvement can be achieved by increasing consolidation of populations, maintaining characteristics of some valuable ancestors, and by removing carriers of deleterious recessive alleles. Some studies in other animals indicate that individuals with low but non-zero inbreeding,

\footnotetext{
S. Mucha $\cdot$ A. Wolc $\cdot$ A. Gradowska $\cdot$ T. Szwaczkowski $(\bowtie)$

Department of Genetics and Animal Breeding,

Poznan University of Life Sciences,

Wolynska 33,

60-637, Poznan, Poland

e-mail: tomasz@jay.au.poznan.pl
}

perform better than outbreds (Szwaczkowski et al. 2004). On the other hand, mating of relatives can lead to inbreeding depression which may cause serious problems. These include an elevated incidence of genetic diseases and disorders, as well as a reduction of fertility, of vitality, of longevity, and even increased mortality. Generally animals from natural populations tend to reduce inbreeding by excluding young males thus avoiding mating of close relatives. Moreover, female cats can control paternity to avoid inbreeding, mainly by selecting non-related mating partners (Ishida et al. 2001). On the other hand in domesticated populations, breeders decide which cats to mate in order to obtain certain desired characteristics or to create a new breed. Unfortunately, domestication and selective mating, often leads to deleterious effects on fitness due to inbreeding. Despite high worldwide interest in purebred cats, little research has been done on the impact of breeding practices on the genetic diversity of cats.

Therefore, in this study we determined the inbreeding level of seven cat breeds registered in The Association of Purebred Cat Breeders in Poland, and evaluated the pedigree completeness over time and the family structure of these breeds.

\section{Material and methods}

Breeds

Pedigree cats have been imported into Poland since the 1930s, but the first information on pedigree cat breeding in Poland was published in 1952 in the Polish Poultry Journal. Since then breeders who wanted to keep purebred animals started their own studbooks, and later joined and created associations. The Association of Purebred Cat Breeders in Poland (SHKRP) was established in 1983. However the 
first exhibition took place in 1982 in Warsaw. The SHKRP was a quickly developing organization and by 1983 joined the world's biggest cat breeder's organization the Fédération Internationale Féline (FIFe). It coordinated cat breeding in Poland, led studbooks, and organized exhibitions. However, the organization was liquidated and removed from FIFe in 2005 and its role was replaced by other organizations.

\section{Persian cats (PER)}

The Persian breed has been under the influence of breeders since the XVth century and it has gone through many changes. Persian cats used to represent a classical conformation of domestic cats. The only difference was their long coat on the tail and abdominal part of the body (Herrscher and Theiling 2002). According to the current standard, Persian cats should be heavily boned and wellbalanced with a sweet expression, soft round lines, and thick coat (CFA 2009). Persian cats were the first cat breed for which births were registered in the Polish Studbook. The first full record of this breed was registered already in 1979, however it must be kept in mind that 3201 cats for which the date of birth was not recorded could have been born even earlier. It is also worth mentioning that over $50 \%$ of animals (13998) recorded by the SHKRP in Poland are Persian cats. This breed together with the Exotic cats had the largest number of breeding dams and sires -3408 and 2025, respectively (Table 1). These two breeds also had the highest average number of kittens per female and male $-4.39 \pm 7.05$ and $7.38 \pm 19.39$, respectively (Table 1).

\section{Exotic cats $(\mathrm{EXO})$}

The Exotic breed was created in the USA, as a result of crossing Persian, American shorthaired and Burmese cats. It was recognized as a breed in 1967 . The main purpose for creating the breed was to obtain cats that would have a similar exterior and character to the Persian cats, but at the same time a coat which is easier to maintain. The exotic cat is a mixture of tender and calm temper specific for the Persian cat and tendency for playing with toys and interest in the surrounding world like in the American Shorthaired (Schneck and Caravan 1997).

British shorthaired cats (BRI)

Ancestors of the British shorthaired cats had been brought to England by the ancient Romans. At the beginning they were bred among themselves with some crossbreeding with local wild cats. The breed gained in popularity in the XIXth century. In 1871 it was shown as a breed in the Crystal Palace cat show. After the Second World War the British cats were crossed with Persian cats, which enhanced their round thickset look (CFA 2009). Based on the number of breeding males and females (554 and 761, respectively) it can be concluded that they have gained quite a lot of popularity among the Polish breeders (Table 1).

\section{Maincoon cats (MCO)}

The Maincoon cat is a native American breed, that originates from Maine. They had been presented at cat shows in 1860's (New York). However at the end of 1800s they lost their popularity so that it was declared extinct in the 1950s. Fortunately that was not true and a group of breeders helped to rebuild the Maincoon breed. By 1976, all cat registries in North America recognized the breed and it gained in popularity. Fédération Internationale Féline registered it as a breed in 1983.

\section{Siberian cats (SIB)}

The Siberian cat is a large semi-longhaired cat originating from Russia. Registrations of the Siberian Cat started in

Table 1 Family structure of cat breeds registered in the Polish herdbook in years 1979 -2004

\begin{tabular}{|c|c|c|c|c|c|c|}
\hline \multirow[t]{2}{*}{ Breed } & \multicolumn{2}{|c|}{ Number of breeding } & \multicolumn{2}{|c|}{ Parents with single kittens } & \multirow{2}{*}{$\begin{array}{l}\text { Average }( \pm \text { SD) number } \\
\text { of kittens per female }\end{array}$} & \multirow{2}{*}{$\begin{array}{l}\text { Average }( \pm \mathrm{SD}) \text { number } \\
\text { of kitens per male }\end{array}$} \\
\hline & dams & sires & female & male & & \\
\hline BRI & 761 & 554 & 538 & 398 & $2.88 \pm 5.68$ & $3.93 \pm 15.56$ \\
\hline $\mathrm{MCO}$ & 807 & 609 & 518 & 432 & $3.29 \pm 6.29$ & $4.16 \pm 13.41$ \\
\hline NFO & 406 & 310 & 283 & 236 & $2.88 \pm 4.54$ & $3.83 \pm 12.82$ \\
\hline PER+EXO & 3408 & 2025 & 1837 & 1183 & $4.39 \pm 7.05$ & $7.38 \pm 19.39$ \\
\hline RUS & 336 & 220 & 199 & 150 & $4.25 \pm 7.52$ & $6.55 \pm 20.26$ \\
\hline SIB & 409 & 279 & 233 & 179 & $4.05 \pm 7.21$ & $5.89 \pm 19.03$ \\
\hline
\end{tabular}

(also cats with unknown date of birth are included)

BRI - British, MCO - Mainecoon, NFO - Norwegian forest cats, PER+EXO - Persian and Exotic, RUS - Russian blue, SIB - Siberian. 
1987 by the Kotofei Cat Club in St. Petersburg. Export started in the end of 1980s. The breed was created out of various cats often taken from streets. Since 1999 there have been also some importations from Northern Asia. Breeding of SIB cats started in Poland in 1990.

Russian blue cats (RUS)

Ancestors of the RUS cats originate from Arkhangelsk in Russia. However the breed itself was created in Great Britain, where the cats were imported in approximately 1800. It was almost extinct after the Second World War which prompted a conservation program in Sweden that resulted in the first documented litter of kittens born in 1960. Afterwards they were exported to many countries in Europe, Asia, and the America's. It is one of a few breeds that has maintained its natural character, and have not been changed much by breeding. It was a very popular breed at the czar's palace in Russia.

Norwegian forest cats (NFO)

Norwegian Forest Cats are well adjusted to the difficult conditions of the northern climate. Their wild ancestors came from cold regions of Scandinavia. The NFO breed was created as a result of casual mating between longhaired wild cats and domestic cats. As a result of selective breeding the recessive allele responsible for long hair was replaced by a short hair allele. It was recognized as a breed in 1972 by breeding associations in Scandinavia and FIFe in 1979. In order to extend colour variants in the breed it was crossbred with Persian cats, which resulted in changes of hair structure of the NFO breed. In order to get a desired head shape some breeders have crossed it with Turkish Angora cat and Balinese cat which has affected the breed's phenotype. This breed has not gained high popularity among the breeders and has one of the smallest number of breeding dams and sires -406 and 310, respectively (Table 1). The NFO cats also had the smallest number of kittens per male and female $-3.83 \pm 12.82$ and $2.88 \pm 4.54$, respectively (Table 1 ).

Data

The data was obtained from the Polish Studbook published by the SHKRP. Animals were born between 1979 and 2004 (for 9215 individuals the date of birth was unknown). The number of herds (Table 2) in the analyzed populations was between 235 (for SIB) and 3057 (for PER+EXO). Overall 26725 cats of the following breeds were included in the pedigree: EXO - 2338, PER - 13998, BRI - 2757, MCO 3173, NFO - 1497, RUS - 1645, SIB - 1914. As Persian reproductors are allowed in the Exotic breed the pedigree of these breeds was analyzed jointly and consisted of 16582
Table 2 Genetic structure of cats, registered in the Polish herdbook, born in 2004

\begin{tabular}{|c|c|c|c|c|c|c|}
\hline Breed & \#Herds & \# ref. & $\begin{array}{l}\text { Founder } \\
\text { equivalent }\end{array}$ & $\begin{array}{l}\text { Founder } \\
\text { genome } \\
\text { equivalent }\end{array}$ & $\mathrm{EH}$ & $\mathrm{RD}$ \\
\hline BRI & 815 & 383 & 121.64 & 15.49 & 0.968 & 0.028 \\
\hline MCO & 1089 & 555 & 98.56 & 16.68 & 0.970 & 0.025 \\
\hline NFO & 506 & 221 & 59.37 & 8.15 & 0.939 & 0.053 \\
\hline $\begin{array}{l}\text { PER }+ \\
\text { EXO }\end{array}$ & 3057 & 712 & 344.82 & 31.12 & 0.984 & 0.015 \\
\hline RUS & 328 & 201 & 47.92 & 7.87 & 0.936 & 0.054 \\
\hline SIB & 235 & 310 & 71.87 & 13.22 & 0.962 & 0.031 \\
\hline
\end{tabular}

Note on symbols: \# ref. - number of individuals in the reference population, EH - expected heterozygosity, RD - random drift, BRI British, MCO - Mainecoon, NFO - Norwegian forest cats, PER+ EXO - Persian and Exotic, RUS - Russian blue, SIB - Siberian.

individuals. That is why in the analysis we show results for six breeds.

Pedigree analysis

A reference population for each breed consisted of individuals born in 2004 (last recorded year). 310 - SIB, 383 - BRI, 201 - RUS, 555 - MCO, 221 - NFO, 712 PER and EXO. Completeness of pedigree information was assessed with equivalent generations. The number of equivalent generations traced was computed as the sum over all known ancestors of the terms $(1 / 2)^{t}$, where $t$ is the ancestor's generation number, which is equal to one for the parents, two for the grandparents, etc. (Maignel et al. 1996).

Inbreeding coefficients were extracted from additive relationship matrix according to algorithm described by Sargolzaei et al. (2005) using software package CFC (Sargolzaei et al. 2006). Inbreeding rate was estimated for four year periods to smoothen trends and filter out temporary distortions.

$\frac{1-F_{t+x}}{1-F_{t}}=(1-\Delta F)^{x}$

where: $F_{t}$ is the inbreeding level in year $t$ and $F_{t+x}$ the inbreeding level $x$ years later (Falconer and MacKay 1996). This leads to the following formula:

$\Delta F_{t}=1-\left(\frac{1-F_{t+2}}{1-F_{t-2}}\right)^{\frac{1}{4}}$

so that $\Delta F_{t}$ is the inbreeding rate in the middle year of a four year period with $F_{t+2}$ the average inbreeding coefficient of animals born two years after year $t$ and $F_{t-2}$ two years before year $t$. 
The founder equivalent or effective number of founders $\left(\mathrm{N}_{e f}\right)$ was computed according to Lacy (1989):

$N_{e f}=\frac{1}{\sum_{i=1}^{N}\left(\frac{c_{i(0, t)}}{N}\right)^{2}}$

where: $c_{i}$ - genetic contribution from founders to generation $t, N$ - number of individuals.

The founder genome equivalent $\left(\mathrm{N}_{g e}\right)$ was computed as (Caballero and Toro 2000):

$N_{g e}=\frac{1}{2 \bar{f}_{t}}$

where: $\bar{f}_{t}$ is the average coancestry for the group considered.

Genetic diversity $\left(G D_{t}\right)$ was estimated according to Caballero and Toro (2000) as:

$G D_{t}=1-\frac{1}{2 N_{e f}}$.

Expected heterozygosity $\left(E H_{t}\right)$ is described by the following formulae given by Caballero and Toro (2000):

$E H_{t}=1-E\left(\sum_{n=1}^{2 N} q_{n, t}^{2}\right)=1-\sum_{n=1}^{2 N} E\left(q_{n, t}^{2}\right)=1-\bar{f}_{t}=1-\frac{1}{2 N_{g e}}$

where $q_{n, t}$ - frequency of allele $n$ at generation $t$ in a given simulation replicate, and the expectation is over replicates.

The difference between $G D_{t}$ and $E H_{t}$ is a measure of average variance of allel frequencies indicating the amount of genetic diversity lost due to random drift $(R D)$ :

$R D=G D_{t}-E H_{t}=\sum_{n=1}^{2 N} E\left(q_{n, t}^{2}\right)-\sum_{n=1}^{2 N} E^{2}\left(q_{n, t}\right)=2 N \overline{V\left(q_{t}\right)}$

Effective population size ('realized' $N_{e}$ ) based on individual increase in inbreeding $\left(\Delta F_{i}\right)$ was calculated following the approach proposed by Gutiérrez et al. (2009). The $\Delta F_{i}$ coefficients were computed as $\Delta F_{i}=1-\sqrt[t-1]{1-F_{i}}$, where $F_{i}$ is the individual coefficient of inbreeding and $t$ is the equivalent complete generations (Maignel et al. 1996). The effective population size $\left(\overline{N_{e}}\right)$ was obtained from $\overline{\Delta F}$, which was computed by averaging the $\Delta F_{i} \mathrm{~s}$ of the $n$ individuals included in a given reference subpopulation as: $\overline{N_{e}}=\frac{1}{2 \overline{\Delta F}}$.

\section{Results}

Persian and exotic cats

Those two breeds had the largest number of registered breeders (Table 2). Nevertheless, until the 1990s the number of registered animals was low (Fig. 1), and their pedigree information was poor. Also 186 Exotic cats with unknown date of birth were imported. Population size rapidly increased in 1996, and since then the number of registered cats has gradually decreased. Since 1988 the inbreeding level has been increasing for both sexes with a $\Delta \mathrm{F}$ of $0.3 \%$ per year reaching an average of $3 \%$ by 2004 (Fig. 2). Some fluctuations of inbreeding, were most likely caused by small import of unrelated animals or exchange of males (used for reproduction) between the breeders. In the last five years of the recording the proportion of inbred individuals reached $68.85 \%$, which is a moderate level in comparison with other breeds. Estimates of effective population size based on individual increase in inbreeding did not vary much over the analyzed period of time (Fig. 3). In the last five years of the recording the $\mathrm{N}_{\mathrm{e}}$ was between 80 and 100 individuals. Two breeders have registered more than 200 cats, and 60 more than 50 cats. Average herd size was 4.26 . In the relatively big breeders average inbreeding coefficients were low, only one breeder had average inbreeding coefficient above $10 \%$. This breeder also had a litter with the highest recorded inbreeding (inbreeding coefficient of 0.376). Small breeders were less aware of high inbreeding. Pedigree completeness has been increasing since the set up of the studbook, and in the 1990s was at a satisfactory level of over $70 \%$. In the beginning of the registration more information was available for females, but since 1995 it has been on a similar level for both sexes. In the last year of the recording average inbreeding coefficient reached $3.8 \%$ for all animals and $5.4 \%$ for inbred individuals (Table 3 ).

The population of Exotic cats was smaller than that of the Persian breed but their pedigree was better documented. Inbreeding was avoided by the use of Persian reproductors or by importing animals. Breeders had smaller herds with only 5 exceeding 50 recorded individuals and they were mostly kept together with Persians. Only one big breeder performed consistent inbreeding, and 43 individuals had an inbreeding coefficient of over $25 \%$. Lower number of single cat breeders resulted in higher average number of cats per breeder 6.1.

\section{British cats}

Breeding of the British cats began in Poland in the 1990s and until 2004 was gradually increasing. In 1999 the number of registered births exceeded 100 , until then the average inbreeding coefficient as well as availability of pedigree information was fluctuating due to small population size. The breed experienced a large increase of $\mathrm{N}_{\mathrm{e}}$ in year 1996 and 1997, when it reached 294 and 672 individuals, respectively (Fig. 3). At the same time it experienced growth in the population size (Fig. 1) and large 
Fig. 1 Number of cats registered in the Polish herdbook in years 1979 -2004; EXO+PER (solid line), BRI (circle), MCO (gray diamond), SIB (gray triangle), RUS (square), NFO (cross)

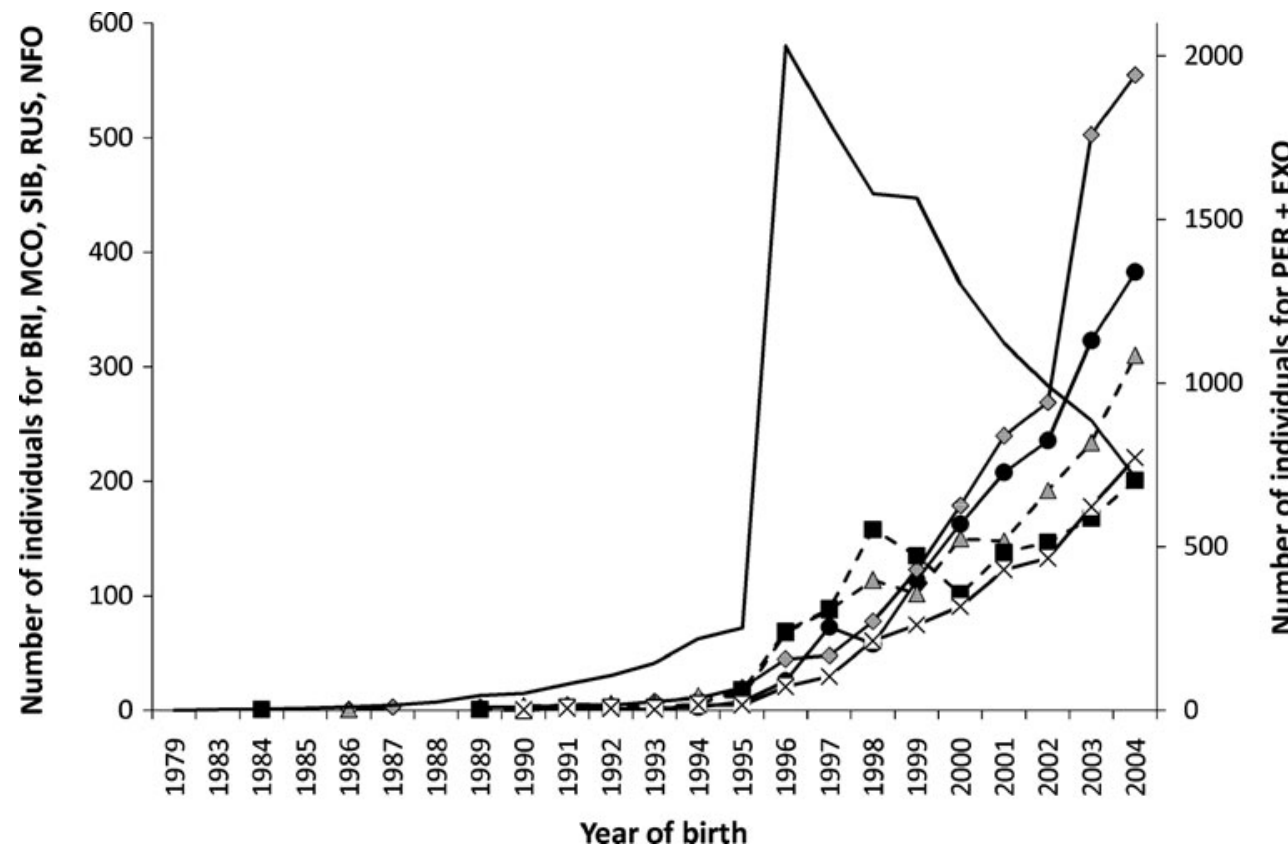

the generation equivalent fluctuated strongly in the analysed period. It indicates that pedigree completeness was lower than in other breeds. Probably this was due to low awareness of the breeders who did not pay attention to accurate record keeping. Moreover, for 555 males and 426 females the year of birth was not known, and their average inbreeding coefficients were 0.7 and $0.6 \%$ respectively. Only seven breeders registered more than 50 cats with a maximum of 282 registered by one breeder.
Fig. 2 Average coefficient of inbreeding estimated for the individuals born in each year, calculated for cat breeds registered in the Polish herdbook In years 1990-2004. EXO+PER (solid line), BRI (circle), MCO (gray diamond), SIB (gray triangle), RUS (square), NFO (cross)

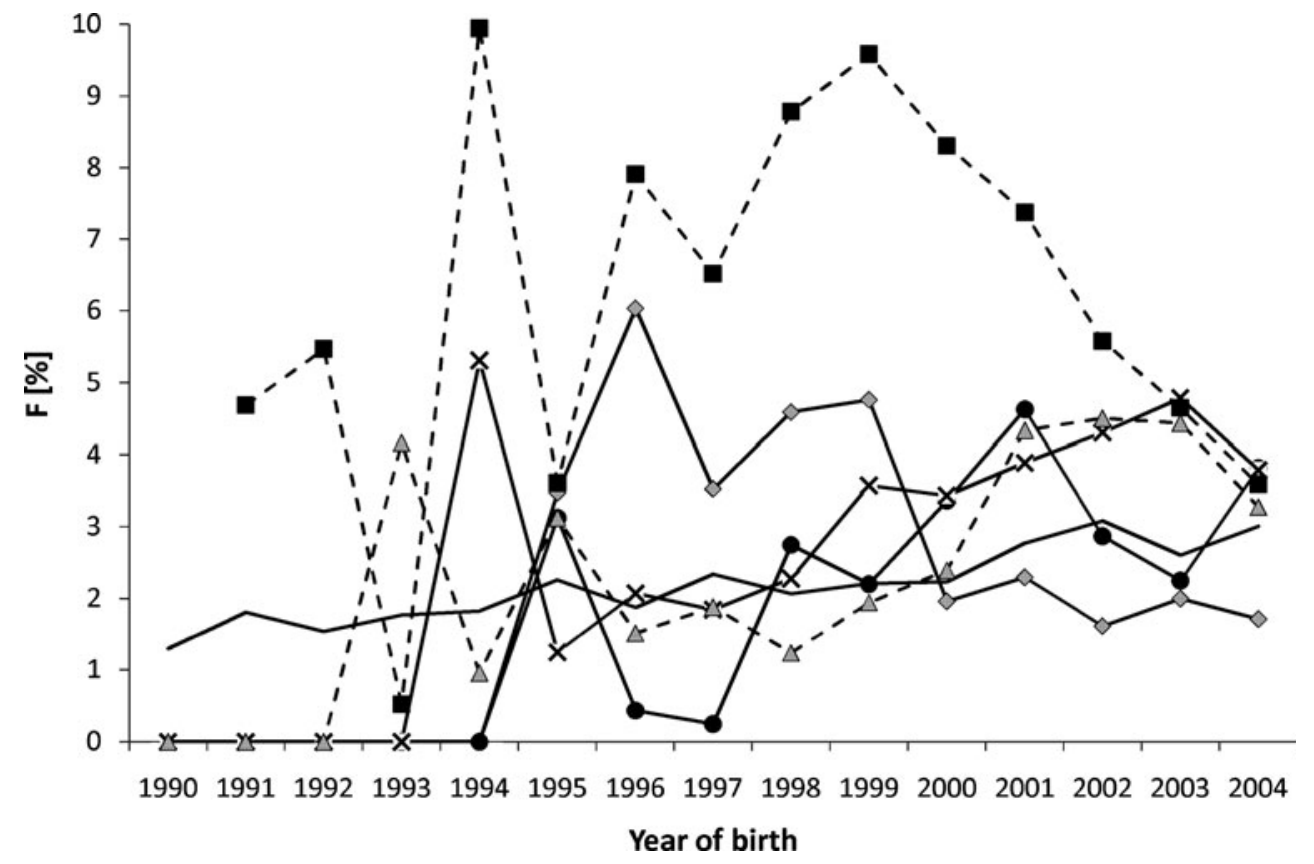


Fig. 3 Effective population size calculated based on individual increase in inbreeding for cat breeds registered in the Polish herdbook in years 1990-2004. $\mathrm{EXO}+\mathrm{PER}$ (solid line), BRI (circle), MCO (gray diamond), SIB (gray triangle), RUS (square), NFO (cross)

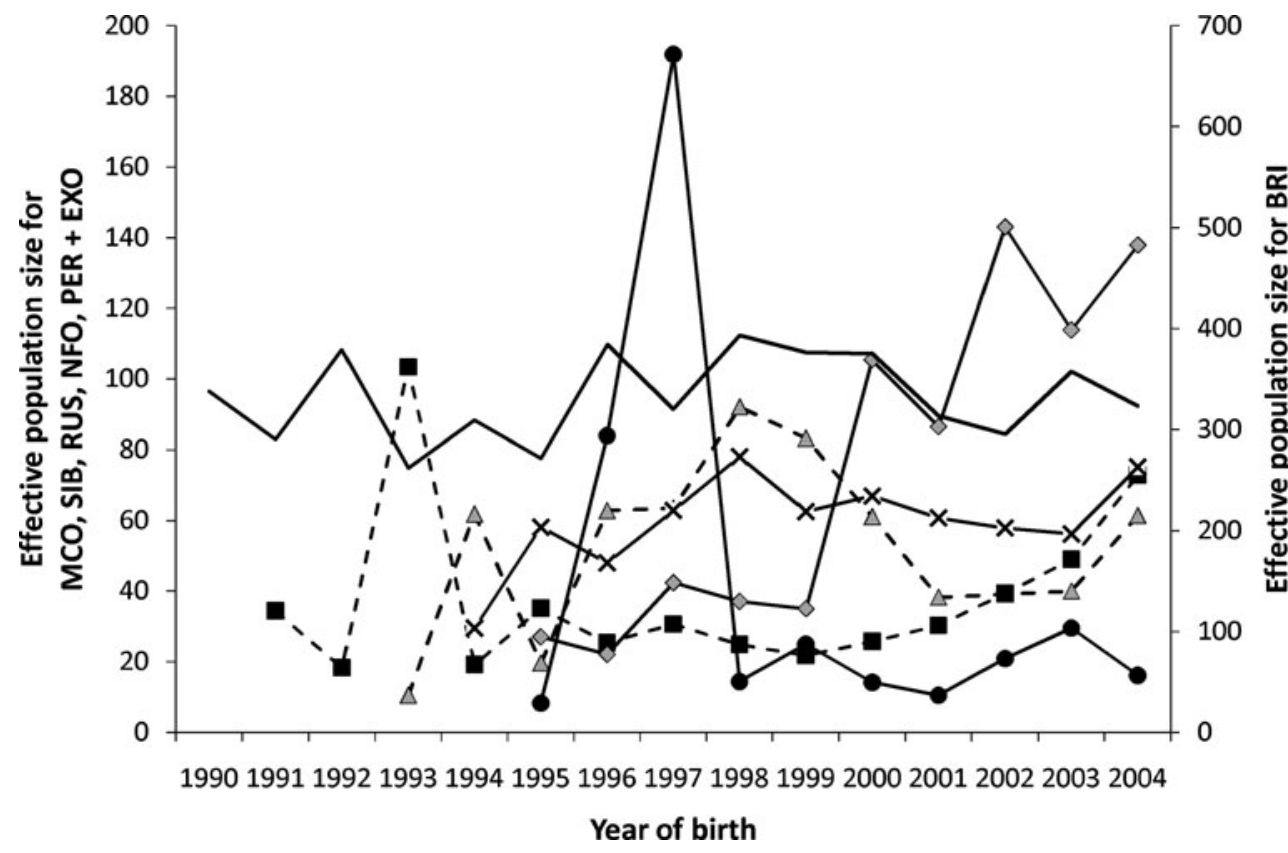

outnumbering even Persian cats. Unfortunately the rapid growth of the population was not accompanied by an increase of accuracy in record keeping. This resulted in low availability of pedigree information Thus inbreeding level was most likely underestimated. In this group 19 males with nonzero inbreeding had average inbreeding coefficient of over $11 \%$, whereas for 21 females it was $7.8 \%$.

\section{Siberian cats}

There were 1786 Siberian cats registered in the Polish Studbook, 332 of which had unknown year of birth. In 1993 one male with high inbreeding of 25\% (sire-daughter mating) appeared which strongly affected average inbreeding level in males. After rapid increase of pedigree completeness until the year 2000 it has stabilized at 83.6\% (Table 3). Inbreeding of males was slightly higher than for females and for three years exceeded 5\% (1993, 2001, 2002). Effective population size of the breed was fluctuating between 10 and 60 individuals until 1996. It experienced growth up to 92 individuals in 1998 and started decreasing afterwards (Fig. 3). Breeders registered on average 5.6 kittens with the biggest stud of 240 cats. Relatively large proportion of animals (532 cats) was not attributed to any breeder. Nonzero inbreeding level was recorded for 638 kittens with an average inbreeding coefficient of $7.36 \%$. Average inbreeding coefficient was the same for males and females $\mathrm{F}=2.63 \%$.

\section{Russian cats}

Until 1996 only a few imported animals constituted the Polish population of Russian cats. Average inbreeding level 
Fig. 4 Percentage of inbred individuals in cat breeds registered in the Polish herdbook in years 1990-2004. EXO+PER (solid line), BRI (circle), MCO (gray diamond), SIB (gray triangle), RUS (square), NFO (cross)

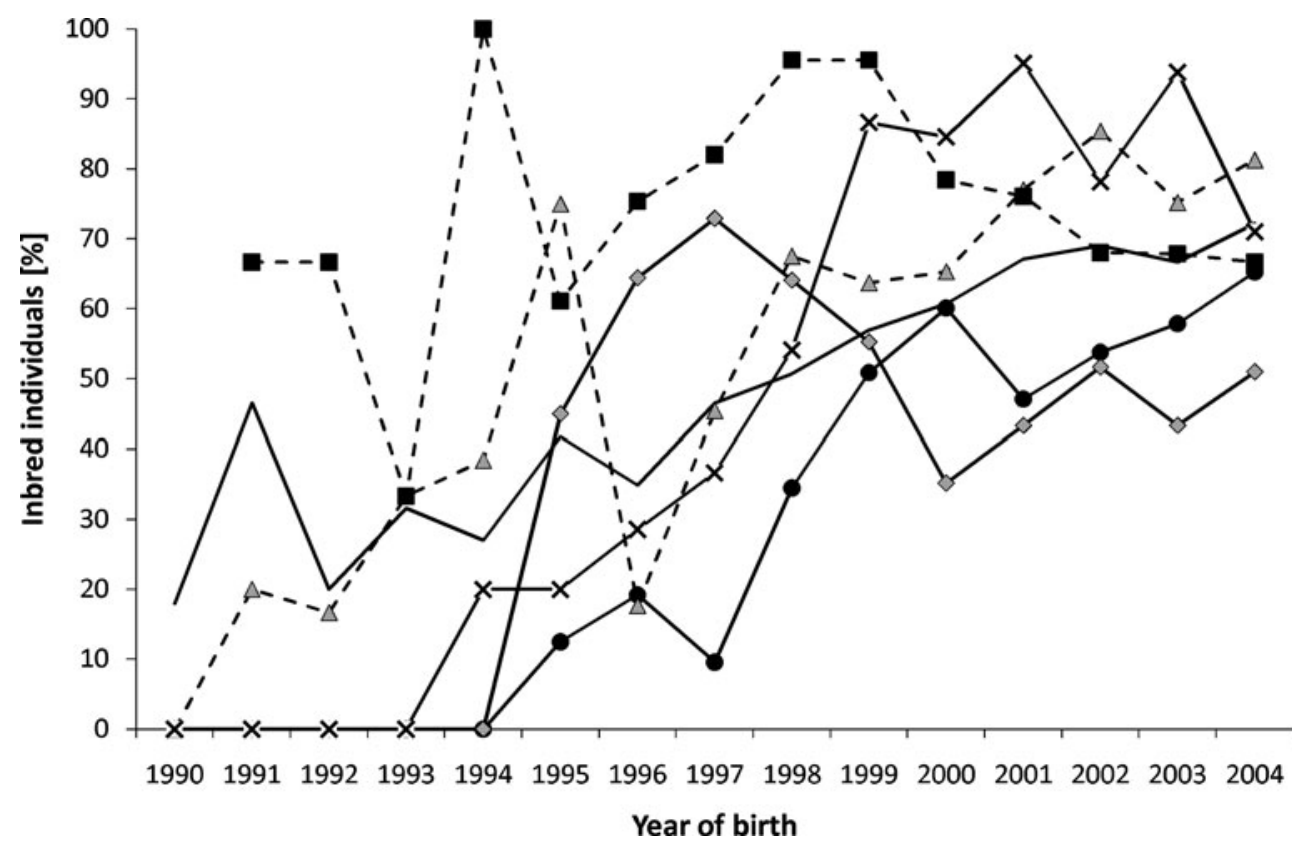

was the highest in this group $(5.4 \%$ for all, and $8.6 \%$ for inbred individuals) which results from the small active population for this breed (Table 1) and some breeders who used close inbreeding $(\mathrm{F}>0.2)$. Until 1999 a high inbreeding rate was recorded with a decreasing trend thereafter. Rapid changes of inbreeding level were related to pedigree completeness and caused by small population size. The Russian breed had one of the highest proportion of inbred individuals $(71.41 \%)$. For animals born in 2004, the founder genome equivalent was equal to 7.87 and the effective number of founders was 47.92. This indicates that due to the small number of founders and breeding within a small and closed population has lead to a considerable loss of genetic diversity. Moreover those estimates are likely to be underestimated as pedigree completeness (expressed as generation equivalent) decreased after 1998 from 5.6 to 1.0 (Fig. 5).

\section{Norwegian forest cats}

Norwegian forest cats were the smallest of the analyzed populations with 1423 registered individuals. The percent-
Fig. 5 Generation equivalent for cat breeds registered in the Polish herdbook in years 19902004. EXO+PER (solid line), BRI (circle), MCO (gray diamond), SIB (gray triangle), RUS (square), NFO (cross)

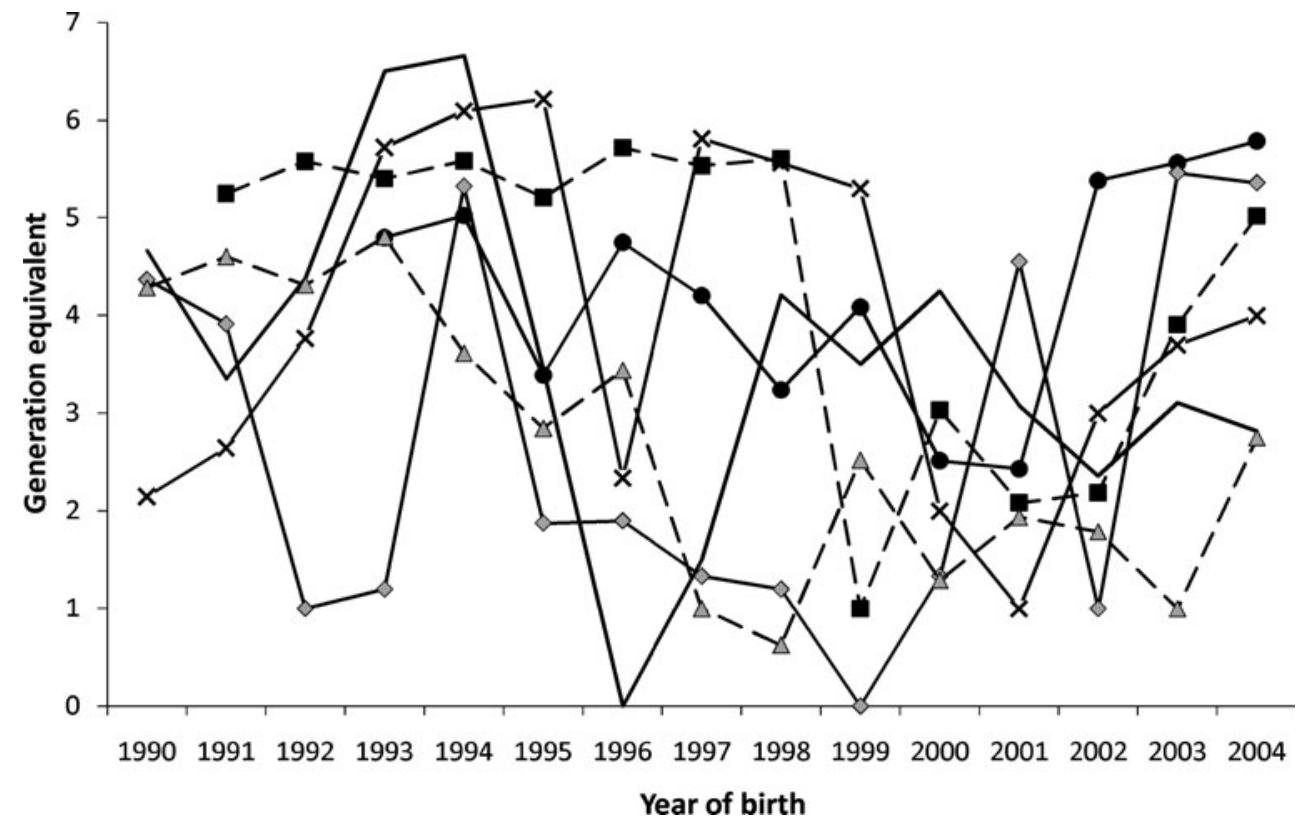


age of inbred animals $(\mathrm{F}>0)$ was increasing very fast (Fig. 4), and was higher than in other described breeds ( $71.0 \%$ in the last year of the recording). First animals with known birth year were registered in the studbook in the early 1990s however the numbers of registrations per year did not exceed 20 until 1998. A year later pedigree completeness reached a level of $90 \%$. An inbreeding level has been slowly but consistently increasing since 1997 at a similar rate in both sexes. Still it has not exceeded the level of $5 \%$ (Fig. 2), which indicates that mating of close relatives has been avoided. The maximal number of registered progeny was 124 for male and 40 for female. Seven sire-daughter matings were recorded in the studbook.

\section{Discussion}

This research was designed in order to evaluate the genetic diversity and threat of inbreeding depression in cats registered in the studbook of the Association of Purebred Cat Breeders in Poland. Pedigrees of seven cat breeds (EXO, PER, BRI, MCO, NFO, RUS, SIB) registered in the Polish Studbook were analyzed. A few reports on inbreeding rate can be found in literature on other domesticated species, e.g. dogs (Leroy et al. 2009). However such analysis has never been done before and therefore our results can provide some insight for people involved in cat breeding. The SHKRP was established in 1981, however some cats had been registered before, as the oldest records date back to 1979 . The number of registered cats was very small until the mid 1990s. Afterwards all of the analysed breeds exhibited growth. Especially the Persian breed, which had almost 2000 registered individuals in the 1996. Such increase in the number of registered cats can be explained by the increasing interest in purebred cat breeding in Poland. It could have been also caused by the socio-economic transformation that occurred in the 1990's. Import of animals became easier and various cat accessories became more available. After the peak in 1996 the number of registered Persian cats has been decreasing, probably because other cat breeds gained on popularity and became more attractive for breeders. Overall population size of all of the analysed breeds can be considered as small (between 200 animals for the RUS and 590 for the MCO were born in 2004). That is why breeding practices can have a huge impact on the level of inbreeding and the amount of genetic diversity maintained within the breeds. It is important to avoid unbalanced breeding schemes, where certain sires are used very frequently. Also high selection intensity can result in high inbreeding (Weigel 2001), that leads to increased homozygosity. Such practices can have detrimental effects on fitness and reproduction of the breed and thus can seriously affect its future development. For instance it has been reported that kitten mortality in Persian cats is $25 \%$ (Sparkes et al. 2006). Another problem of the Persian breed is the occurrence of brachycephalic upper airway issues (Gunn-Moore et al. 2008). Other examples of defects prevalent in pedigree cats include type II diabetes mellitus in the Burmese cats from the UK, Australia and New Zealand, which are four times more likely to develop the disease than other cats (Rand et al. 1997).

However, results of the current analysis suggest that none of the analysed cat breeds is threatened by high inbreeding level. In the last years of the recording, the highest estimates of inbreeding were in the SIB, NFO and RUS and reached around $6 \%$. However, estimates of inbreeding rate were close to zero and in some cases even negative. They were much smaller than the limit of the FAO guidelines of $1 \%$ above which breeds are classified as threatened with extinction (FAO 1998). Also effective population size based on individual increase in inbreeding was above 50 for most of the breeds. Overall, all of the cat breeds registered in the Polish studbook do not seem to be endangered by the negative effects of inbreeding.

The highest inbreeding level was found in the Polish population of Russian cats. It reached above $10 \%$ in 1999 and decreased thereafter down to around $4 \%$. At the same time pedigree completeness decreased from 5.6 to 1 generation equivalent. Therefore the estimated inbreeding coefficient is most likely underestimated. Animals with unknown parents are considered as not related to the population. Therefore they and their offspring are assumed to have an inbreeding coefficient of zero. In fact they are somewhat related to other members of the population. There are many ways to estimate the effect of gaps in the pedigree on the coefficient of inbreeding (VanRaden 1992; Croquet et al. 2006; Cassell et al. 2003). Accurate pedigree records can also be obtained using DNA analysis in case of individuals with unknown parents (Fernandez et al. 2005). This however, was outside the scope of the current research. Unfortunately, to our knowledge there are no reports on inbreeding levels in cats in the literature. Therefore it was not possible to compare the analysed populations of Polish cats to cat breeds in other countries.

The effective number of founders was the lowest in the RUS and NFO breeds and accounted for 48 and 59 founders, respectively. They also had the lowest number of founder genome equivalents that reached around 8 founder genomes. This can be partially explained by the fact that those populations were formed out of a very limited number of founders. Moreover they have not gained much popularity among breeders and were kept in a small number. This resulted in the smallest number of animals born each year (201 and 221 individuals born in 2004 respectively). Especially in case of the RUS breed, until 1999 there had been some periods with increased mating of 
relatives, which was reflected by a high mean inbreeding in the population. Apart from inbreeding another driving force that led to loss of genetic diversity was random drift. Estimated genetic diversity based on the effective number of founders and genome equivalents had been computed and the difference between them was the estimated loss of genetic diversity due to drift in the non-founders (Caballero and Toro 2000; Honda et al. 2004). It was the largest in those two breeds and accounted for around 5\%. That is why the RUS and NFO breeds should be monitored in the future to avoid rapid increase of homozygosity and the related problems.

Also the analysis of the effective population size, based on individual increase in inbreeding, suggests that the RUS and NFO breeds should be monitored. In the last years of the recording $(2000-2003)$, they had $N_{e}$ between 30 and 60 individuals, that went up to 75 in the last year of the recording (2004). The analysis of the realized $\mathrm{N}_{\mathrm{e}}$ also revealed that the SIB breed had the lowest effective population size, between 38 and 60 in the last years of the recording (2000-2004). Analysis of inbreeding rate was not appropriate for the analyzed populations. As a real populations with complex pedigree and genetic history it did not conform to the main assumptions underlying this method (idealised population). As a result in many cases the $N_{e}$ was negative, which was not true. Thus an analysis of the realised $N_{e}$ was performed. It can be considered as more informative because it does not dependent on the population mating policy but on the matings performed throughout the pedigree of each individual (Gutiérrez et al. 2008). Moreover estimates of realised effective population size can account for size of their founder population, their mating policy and bottlenecks due to excessive use of certain animals (Cervantes et al. 2008). Realised $N_{e}$ was more suitable in case of cat breeds, which had issues with pedigree completeness, as this method accounts for differences in pedigree knowledge and completeness at the individual level Gutiérrez et al. (2008).

Most of the big breeders were aware that mating of related individuals is disadvantageous. However, in many cases small herds had inbreeding levels which were much higher than the population average. This problem could be easily solved by some occasional use of unrelated males from other breeders. Based on the analysed data it can be concluded that all of the studied breeds are not threatened with excessive inbreeding. Mating between close relatives seemed to be avoided and thus the increase in inbreeding was low. Nevertheless some breeds such as the RUS, NFO and SIB should be monitored in the future. Their inbreeding rate seems to be on an acceptable level, but the analysis of the realised $\mathrm{N}_{\mathrm{e}}$ showed that it fluctuates over the years and sometimes drops to values that raise some concern. Above all accurate record keeping is essential to ensure proper completeness of pedigrees and thus to obtain accurate estimates of all of the analysed parameters. Pedigree completeness expressed as generation equivalent was fluctuating strongly in the analysed period of time (1990 -2004).

As a conclusion of this study a relatively low inbreeding level has been registered in the analysed pedigreed cat populations and they are not threatened by undesirable effects of homozygosity.

Acknowledgements The authors would like to express their gratitude to the Association of Purebred Cat Breeders in Poland for providing data used in this research. We are also grateful to the anonymous reviewer who contributed to the improvement of this manuscript.

\section{References}

Caballero A, Toro MA (2000) Interrelations between effective population size and other pedigree tools for the management of conserved populations. Genet Res 75:331-343

Cassell BG, Adamec V, Pearson RE (2003) Effect of incomplete pedigrees on estimates of inbreeding and inbreeding depression for days to first service and summit milk yield in Holsteins and Jerseys. J Dairy Sci 86:2967-2976

Cervantes I, Goyache F, Molina A, Valera M, Gutierrez JP (2008) Application of individual increase in inbreeding to estimate realized effective sizes from real pedigrees. J Anim Breed Genet 125:301-310

CFA (2009) Cat Fanciers' Association http://www.cfa.org/ (last accessed May 25th 2009)

Croquet C, Mayeres P, Gillon A, Vanderick S, Gengler N (2006) Inbreeding depression for global and partial economic indexes, production, type and functional traits. J Dairy Sci 89:2257-2267

Falconer DS, Mackay TFC (1996) Introduction to quantitative genetics, 4th edn. Longman, Harlow

FAO (1998) Secondary guidelines for development of national farm animal genetic resources management plans. FAO, Rome

Fernandez J, Villanueva B, Pong-Wong R, Toro MA (2005) Efficiency of the use of pedigree and molecular marker information in conservation genetics. Genetics 170:1313-1321

Gunn-Moore D, Bessant C, Malik R (2008) Breed-related disorders of cats. J Small Anim Pract 49:167-168

Gutiérrez JP, Cervantes I, Molina A, Valera M, Goyache F (2008) Individual increase in inbreeding allows estimating realised effective sizes from pedigrees. Gen Sel Evol 40:359-378

Gutiérrez JP, Cervantes I, Goyache F (2009) Improving the estimation of realized effective population sizes in farm animals. J Anim Breed Genet 126:327-332

Herrscher U, Theiling H (2002) Rasy kotow. Der Kosmos Katzenfuhrer. Multico, Warsaw

Honda T, Nomura T, Yamaguchi Y, Mukai F (2004) Monitoring of genetic diversity in the Japanese Black cattle population by the use of pedigree information. J Anim Breed Genet 121:242-252

Ishida Y, Yahara T, Kasuya E, Yamane A (2001) Female control of paternity during copulation: inbreeding avoidance in feral cats. Behaviour 138:235-250

Lacy RC (1989) Analysis of founder representation in pedigrees: founder equivalents and founder genome equivalence. Zoo Biol $8: 111-124$

Leroy G, Verrier E, Meriaux JC, Rognon X (2009) Genetic diversity of dog breeds: within-breed diversity comparing genealogical and molecular data. Anim Genet 40:323-332 
Maignel L, Boichard D, Verrier E (1996) Genetic variability of French dairy breeds estimated from pedigree information. Interbull Bull 14:49-54

Rand JS, Bobbermien LM, Hendrikz JK, Copland M (1997) Over representation of Burmese cats with diabetes mellitus. Austr Vet J 75:402-405

Sargolzaei M, Iwaisaki H, Colleau JJ (2005) A fast algorithm for computing inbreeding coefficients in large population. J Anim Breed Genet 122:325-331

Sargolzaei M, Iwaisaki H, Colleau JJ (2006) CFC (Contribution, Inbreeding (F), Coancestry) Release 1.0 . A software package for pedigree analysis and monitoring genetic diversity
Schneck M, Caravan J (1997) Koty od A do Z. Oficyna Panda, Warsaw

Sparkes AH, Rogers K, Henley WE, Gunn-Moore DA, May JM, Gruffyddjones TJ, Bessant C (2006) A questionnaire-based study of pedigree cat breeding in the UK. J Feline Med Surg 8:145-157

Szwaczkowski T, Cywa-Benko K, Wężyk S (2004) Curvilinear inbreeding effects on some performance traits in laying hens. J Appl Genet 45:343-345

VanRaden PM (1992) Accounting for inbreeding and crossbreeding in genetic evaluation of large populations. J Dairy Sci 75:3136-3144

Weigel KA (2001) Controlling inbreeding in modern breeding programs. J Dairy Sci 84:177-184 